\title{
A.JOTE
}

African Journal of Teacher Education

ISSN 1916-7822. A Journal of Spread Corporation

Volume 10. No. 12021 Pages 106-126

\section{Effect of Visualized Case-Based Learning Strategy on Students' Academic Performance in Chemistry in Ibadan Metropolis, Nigeria}

\author{
Mabel Ihuoma Idika \\ Department of Science and Technology Education, \\ University of Ibadan, \\ Nigeria
}

\begin{abstract}
This study investigated the effect of the use of visualized case-based learning (VCBL) strategy on chemistry students' academic achievement. The theoretical framework for this study is based on Thorndike's idea of transfer of learning. A sample of one hundred and forty-five (145) senior secondary school II chemistry students drawn from four intact classes in two local government areas of Ibadan metropolis, were used for the research. Three well validated instruments were used to collect data. The VCBL package was developed following the Smith and Ragan Instructional System Design (ISD) Model (1999). This model comprises four stages: namely, Analysis, Design, Development and Implementation/Evaluation. Data were analysed by means of inferential statistics (ANCOVA, EMM and Tukey's post-hoc). Results showed that there is significant main effect of treatment on students' achievement in Chemistry $(F(2,248)=17.539$; $p<0.05 ; \eta 2=0.124)$; implying that the posttest scores of students' achievement in achievement significantly differ between the treatment and conventional groups. It was concluded that VCBL strategy has the potential to enable students understand chemistry better by way of promoting transfer of learning. In light of this, implications were discussed and relevant suggestions made.
\end{abstract}

Keywords: visualization, cased-based learning, chemistry, inquiry, achievement 


\section{Introduction}

Chemistry is central to all the physical sciences and is seen in virtually every aspect of life and it is central to man's existence and survival. Any nation that must develop cannot deny the place of chemistry in nation building and sustenance of development. The employment of chemistry principles dates back to the Stone Age when the early man discovered fire. Presently, the knowledge of chemistry is visible in almost all sectors of human endeavour. It is applied in the areas of food and agriculture, manufacturing industries, health/ pharmaceuticals, power, works and housing, transportation, mineral exploration, space exploration, textiles, oil and gas, water treatment and almost all forms of engineering.

By studying chemistry, students acquire scientific awareness and knowledge of their environment as well as information about the world around them. As a school subject, students basically rely on basic qualities like reasoning and creative skills. Learning chemistry also requires an individual's capacity to engage cognitive, affective and psycho-motor skills (Woldeamanuel, Atagana and Engida, 2013). One of the aims of chemistry education in senior secondary schools is to show chemistry and its link to industry as well as everyday life. In addition, students also "develop and exhibit skills such as inquiry, critical thinking, objectivity, rational reasoning, experimenting, logical deductions, logical reasoning, among others" (Idika and Adesoji, 2020). Olaleye (2012) rightly stated that chemistry provides answers to our natural curiosity about the world and allows learners to experience scientific methods which help in everyday life and in the understanding of

Nigerian students usually do chemistry as science students in the senior secondary schools. A distinction or credit pass in $\mathrm{O}^{\prime}$ level chemistry is usually a requirement for studying any science (physical) related course such as Medicine, Biochemistry, Engineering and Nursing in any higher institution, especially the University. The knowledge of this science subject equips individuals with the requisite problem-solving skills and sound judgment to function effectively in industries and the society in general. Furthermore, chemistry students have a better chance in understanding global problems such as water and air pollution, poverty and global warming. He or she should be able to recognize, analyze, evaluate and suggest innovative solutions to these problems. 
But, some researchers have asserted that despite the attempts made to improve pedagogical practices in chemistry, students' performance in examinations in the subject, especially in Nigeria, remains a source of concern (Nbina and Vico,2010; Ezeudu and Obi,2013). Statistics obtained from West African Examination Council (WAEC) on students' performance in chemistry from 2005-2016 show that students showed a dwindling performance.

There is a notion that the persistent poor performance of students in Chemistry is partly caused by their anxiety caused by the perception that Chemistry is difficult, continued use of conventional teaching strategies and other teacher-centered methods inadequate infrastructures and teaching materials, teaching problems, non-availability of professional and well-trained teachers, lack of technical/laboratory assistants, non-existence of effective problem solving strategies, poor reasoning and poor Mathematics background (Jegede, 2007; Aluko, 2008, Nbina and Vico, 2010; Kolomuc, 2012; Woldeamanuel, Atagana, and Engida, 2013, Nbina (2012), Ali (2012) and Nnoli (2015).

There seems to be a prevalence of the use of conventional teaching methods in most chemistry classrooms (Omwirhiren and Ibrahim, 2016). At best, the learning process is rigid and seems unappealing to the students. Concepts are often taught devoid of opportunities for students to relate what is taught in class and everyday life. Also, instead of promoting students' reasoning and critical thinking capability, the learners spend additional time on writing notes and practically, looking at the board or just listening to the teacher. Achimugu (2012) described conventional teaching strategy as theoretical, boring, disconnected and artificial. Perhaps, the traditional approach to teaching chemistry poses a barrier in attaining the required success in chemistry education and there is an obvious need to adopt more innovative approaches to teaching the subject.

Case-based Learning (CBL) is one of the instructional strategies that is derived from constructivist theory. It is an inquiry-based teaching strategy because it uses case studies as tools to activate learning. A case study is a typical story that engages the reader by presenting an impasse that can only be solved with a basic knowledge of scientific principles (McLean, 2016). Case-Based Learning has been employed in the instructional practices in several disciplines and courses such as Medicine, Law, Psychology and other subject areas apart from science. Casebased instructional practices create an atmosphere that elicits curiosity, interest and delight in the 
process of learning a task (Yalcinkaya, Geban and Ozkan (2012). Research has also shown that this pedagogical strategy, if appropriately utilized, is capable of developing students' ability to think critically, solve problems, develop attitudes and skills, excel in verbal and written tasks, increase motivation and judge self objectively(Williams, 2005). Cases are not mere examples or illustrations but serve as primary structure for learning to take place. (Allchin, 2013). In addition, a Case-Based Learning class provides a stimulating, engrossing and interesting environment where learners can broaden the desire to cooperate and engage others through discussions and sharing of ideas with their classmates in a teacher-facilitated environment. The students are usually placed in small groups thereby providing opportunities for them to recognize misconceptions and acquire a different orientation towards the concept (Williams, 2005).

Cases are usually made in two parts: (1) the case scenario or story/narration of an event for the purpose of instruction and (2) the questions relating to the case or story narrated. In some instances, cases are presented before the questions while in other situations the reverse is the case. According to Cam and Geban (2013), cases are to steer students' thoughts toward a conclusion or provide resources and relevant context for group discussion or a structured, constructive debate in class. The stories or cases may be presented in varying forms. They may be in oral, print or electronic form, for instance, video. In this study, cases are presented to students in such a way that the characters can be seen and heard, it is therefore termed as Visualised Case-based learning. A set of questions relating to the selected cases that can aid students to appraise the possible conclusions, perceptions, and subjects in the case are directed to the learners for the evaluative purposes. Also, an interesting case is expected to facilitate class/group discussions (Williams, 2005) because learners are tasked to solve the problems presented in the case studies using their background knowledge.

Almost all instructors who have investigated the efficacy of Case-Based Learning asserted that it is an excellent way to get students to scrutinize information, identify the vital aspects of a concept and distribute the presentation of challenging material (Yadav, Lundeberg, DeSchryver, Dirkin, Schiller, Maier and Herreid, 2004). The majority of teachers also confirmed their willingness to initiate case studies and other Case-Based Learning strategies in their future teaching (Rybarczyk, Baines, McVey, Thompson, and Wilkins, 2007). Cam and Geban (2013) stated that most chemistry teachers are concerned with innovative, effective and exciting means of teaching chemistry concepts to students. They, therefore, concluded that CBL instruction was 
not only effective in improving students' knowledge of Chemistry; it also was efficacious in the elimination of certain misconceptions. In addition, the use of CBL in a chemistry class enhances meaningful learning since it is interactive and allows for students' active participation. Furthermore, Cam and Geban (2017) carried out an experiment involving 51 freshman primary pre-service teachers from an urban university in Turkey. At the end, the researchers concluded that Case-Based Learning motivates and improves students' attitudes to chemistry. Okediji (2015) also concluded that Case-based Learning had better effects on students' learning outcomes (achievement and attitude) in chemistry than conventional teaching.

In addition, one way to improve both students' performance and interest in science is the use of different teaching approaches with illustrative tools such as graphs, animation, sound and video-clips. In a related study, Turkoquz (2012) investigated students' attitudes to the use of visual media tools in a chemistry laboratory in Turkey. The findings of the study showed that using visual media tools in chemistry laboratory contributes positively to students' behaviour, interest, skills and attitude to chemistry laboratory courses. Also, Berk (2009) submitted that watching a video programme, usually incites both external and even deep feelings and emotions which could be in form of exhilaration, anger, laughter, entertainment, love, and in some situations, boredom. Berk noted that these emotions are often provoked by specific visual scenes, the actors, and/or the background music. In fact, a video can have a strong effect on an individual's intellect and senses.

A video can capture students' attention, generate interest and encourage general participation. It is also believed to make students learn more while increasing motivation (Cruse, 2013). The appropriate use of relevant video clips in the classroom may be most effective for introductory courses or introducing complex topics to lower achieving students and visual/spatial learners (Abram, 2012). One of the aims of the newly revised chemistry curriculum for secondary schools in Nigeria is to "show chemistry and its link with industry, everyday life activities and hazards". It is suggested that chemistry ought to be taught in a more realistic manner. Hence, the need to use Visualised Case-Based Learning since it can provide real-world context and cultural relevance of the topic taught (Abram, 2012). This is likely to foster meaningful learning and promote transfer of learning. 
Therefore, this study investigated the effect of using visualized case-based learning on secondary school students' performance in chemistry.

\section{Hypothesis}

$\mathrm{H}_{0} 1$ : There is no significant main effect of treatment on students' achievement in chemistry

\section{Theoretical framework}

\section{Theory of Transfer of Learning}

Consequent on the scope and nature of this study, the theory of Transfer of Learning was chosen as the anchor of research. The theory generally conveys the idea in transmitting the knowledge and skills that a learner has acquired across two or more situations or tasks. It is believed that the goal of education is for an individual to be able to carry what he has learnt from one environment to make problem-solving decisions in a new environment (Day and Goldstone, 2012; Hajian, 2019). This implies that when concepts are taught well, learners are able to connect, relate and apply them in everyday life as well as outside the school. Visualised case-based learning as an instructional tool engenders the transfer from theory to practice (McLean, 2016).

In other words, 'transfer of learning' represents the reliance of a person's behaviour, performance or learning on his prior experience. This view was originally presented as transfer of practice by Edward Thorndike and Robert S. Woodworth in the $20^{\text {th }}$ century. They explored how individuals would transfer what they have learned from one context to the other. This is concerned with how an upgrade in a cognitive function can affect an associated situation. This theory pointed toward the belief that transfer of learning depends on recognizable similarities between the learning task and transfer task. This was further explained by Thorndike's Theory of identical elements. Most cases of transfer in learning occur in situations that are very similar.

In a constructivist environment, where learners construct their own learning, they acquire new perceptions based on previous knowledge. This is facilitated when they are able to make connections between what they have learnt before and what they are presently exposed to (Hajian, 2019). In their article published in 1992, Perkins and Salomon pointed out that for one to say that learning has taken place; it simply means that the learning can be used in another context. This idea has its locus in the situation where a learner either acquires new knowledge or solves a new problem based on recognizing familiarities among the two situations (Steiner, 2001). Within a 
VCBL class, students engage in the process of watching videos of events and objects they already know. Meaningful learning is expected to take place as this previous knowledge is used to unravel the problems in the cases provided.

More importantly, the theory of transfer of learning is presented in this present time as the extent to which prior knowledge or experiences influence the knowledge acquisition or learning in a new situation (Haskell, 2001). Learner is able to make sense of the dynamics of a new situation with already learnt knowledge. This was buttressed by Charles Judd proposed the Theory of Generalization experience. Judd's theory states that what is learnt in a task ' $\mathrm{X}$ ' can be transferred to task ' $\mathrm{Y}$ ', if when studying ' $\mathrm{X}$ ', the learner is able to create a connection between similarities in both ' $\mathrm{X}$ ' and ' $\mathrm{Y}$ '. Experiences, habits, knowledge acquired in one situation can all be generalized, transferred and applied to situations that are similar. The theory further states that the intellectual ability of an individual could determine his/her ability to generalize knowledge (Sharma, 2015).

The process of transfer become practically involuntary when an individual has mastered the content that is being transferred. In cases where the new concept to be transferred is similar to the original situation that has already been mastered or learned, the differences will be catered for at the subconscious level. Haskell (2001) also explained extensively that 'transfer of learning' is a thought/knowledge process and not just the product of instructional strategies or learning method. Most tasks are connected in one way or another while others are fairly disconnected from each other. When learners attempt to transfer the knowledge of a situation in solving a problem that seems far-fetched, they do not automatically perceive the relationship between the problems. This is referred to as a far transfer and it usually requires a painstaking examination of the situation through profound consideration of the problems (Perkins and Salomon, 1992).

The theory of near and far transfer is a relative concept in the process of teaching and learning because while some learners are able to carry out transfer between seemingly unrelated problems, others may not. This implies that the ability to transfer the knowledge that has acquired to a fairly dissimilar situation is not common to all students.

Unlike the postulations of Thorndike, Woodworth, the theory does not explain how the processes that foster far transfer can be inculcated in learners. Low-road transfer is the development of skills that prompt transfers to attain the level of automation. This process is 
perfected after several sessions of practice in different situations. Simple tasks such as tying a shoelace, operating a cell phone, and driving a motor vehicle are common instances of skills where such automation can be accomplished. High-road transfer entails a conscious cognitive processing to understand; an active and deliberate action to analyse; and a purposeful application of knowledge across career-paths. It is an advanced form of transfer because it requires a deliberate creation of an idea to be transferred and a conscious use of the idea if and when confronted with a situation that requires the idea (Perkins and Salomon, 1992).

\section{Visualised Case-based Learning and Students' Achievement in Chemistry}

In his unpublished doctoral thesis, Okediji (2015) determined the effect of Case-based learning, Observational learning and conventional strategies on students' learning outcomes (achievement in and attitude to) chemistry. Out of 368 students who participated in the study, 135 of them were taught some chemistry topics (chemical reactions, ionic equations, redox reactions and ionic theory) using stories that were verbally narrated by the teacher. The findings of the study indicate that CBL was more efficacious in improving students' learning outcomes in chemistry. However, Geelan and Mukherjee (2010) opined that the use of several representations can be helpful in reminding teachers and learners that our best understandings of scientific phenomena are often models of reality rather than the reality itself. No doubt, visualizations play a vital and essential role in education, especially in learning science. When Woldeamanuel, Atagana, and Engida (2013) conducted a survey of causes of students' negative disposition to chemistry, $77 \%$ of the students complained that chemistry is too abstract because they have never seen most of the things being taught. This, they argued, contradicts the key reason for teaching and learning chemistry. Therefore, the researchers insisted that chemistry should be studied in a way that will enable students to identify the link between chemistry and industry, the environment and daily life in terms of its advantages and demerits. Since, science subjects and topics are widely perceived as difficult and abstract, the use of visual aids to bridge the gap between content and instruction is hoped to make learning of science-related concepts relatable and concrete.

Findings from various studies have stressed that there are numerous advantages in the use of visual and audio equipment in the process of instruction especially with reference to improvements in students' achievement. When compared to conventional/traditional teaching methods, CBL has been shown to have a positive influence on students' learning outcomes in 
areas such as reasoning, the ability to make objective judgments, problem-solving skills, students' retention, higher-order skills on Bloom's taxonomy, and awareness of ethical issues such as students' attitudes, class attendance. One of the great benefits of using cases to teach is that teachers get students' attention because most students enjoy stories (Cam and Geban, 2013).

To buttress this, the work and findings of Rybosczyk et al (2007) showed that students exposed to case study-based learning performed significantly better and demonstrated use of higher-order thinking skills than those that were not taught with CBL. The researchers also submitted that students correctly answered questions that addressed misconceptions about cellular respiration than those in the conventional group. In contrast, when Geelan and Mukherjee (2010), experimented on the use of a computer-based scientific visualization, results indicated that teaching with visualizations did not make any significant impact on learning outcomes when compared to teaching without visualisations. Recent studies showed that when teaching strategies are combined with technology, misconceptions decrease (Turkmen and Usta, 2007). The use of technology as an adjunct in teaching was found to be motivating and created a conducive environment for students' learning, participation, communication and knowledge-sharing in a wide range of ways (Turkmen and Usta,2007).

\section{Statement of the Problem}

Chemistry as a science subject is often regarded as difficult and abstract. Perhaps, this is having an adverse effect on learners' performance especially with respect to achievement. Research shows that if what is learnt in the classroom is not transferable to a new situation and learners are not able to make connections between concept and everyday life, learning goals may not be achieved. It appears that this results from the use of uninteresting conventional teaching. Research shows that teaching approaches which provide real-world context and cultural relevance of the topic taught can facilitate meaningful learning and encourage transfer of learning. One of such is Case based learning. Cases can be presented in various forms but there is a dearth in literature on the use of visualized cases. Visualizations (which includes the use of videos) can elicit and improve students' attention, motivation to learn and eliminate misconceptions. Perhaps, this could lead to better academic achievement in chemistry.

Therefore, this study determined the effect of visualized case-based learning on students' achievement in chemistry in Ibadan metropolis, Nigeria. 


\section{Methodology}

\section{Population and sampling techniques}

The population of the study comprise all chemistry students in senior secondary schools in Ibadan metropolis. The sample participants comprised 145 senior secondary school II chemistry students from four purposively selected government public (mixed) schools from two local governments in Ibadan metropolis which were selected by random sampling.

From four of the six schools selected, an intact class each of SSII chemistry students was chosen to participate in the study, making a total of four (4) intact classes. The intact classes were randomly assigned to visualised CBL (experimental group) and conventional teaching group was the control. The students were taught some selected chemistry topics (water, water pollution, solutions and solubility)

\section{Research Instruments}

Three adequately validated instruments were developed and used in this study. They are:

1. Teacher Instructional Guide for Visualised CBL (Lesson plan): This comprises

$\checkmark$ Cases recorded in a Video CD

$\checkmark$ A worksheet containing questions and spaces for students to put down their answers or opinions

$\checkmark$ A lesson plan for the teacher to use to teach the concept

2. Teacher Instructional Guide for Conventional Teaching Strategy

3. Chemistry Achievement Test $(\alpha=0.73)$

\section{Development and Validation of the Video CD}

Four cases for each of the four lesson plans used in the study were created and written by the researcher. The cases were developed based on the principles highlighted by Herreid (2004). The cases were subjected to scrutiny by chemistry teachers and Chemistry Education experts. Based on the comments received, some changes were made in terms of grammar, language of presentation and logic. The final writings were handed over to the experts in Educational Technology for development of the Visualized Case-based Learning package.

The Video CD which bears the cases to be viewed in the Visualized CBL class was designed and developed by the researcher along with experts in Educational Technology. The 
package was developed following the Smith and Ragan Instructional System Design (ISD) Model (1999). This model comprises four stages; namely, Analysis, Design, Development and Implementation/Evaluation. After production, the video was presented to 20 students who would not be part of the study and 6 Chemistry teachers. The students answered the questions on the worksheet. The teachers were also asked to fill a rubric for evaluating educational videos. Their responses were used to judge the videos in terms of relevance, timing, clarity of ideas, quality of sound and pictures. The average value obtained was 4.2.

\section{Pre-test}

Chemistry Achievement Test (CAT) administered to all the subjects (both experimental and control groups).

\section{Experiment}

During the experiment, the teachers taught the topics using the Teacher Instructional guide for visualized CBL for a duration of six (6) weeks. The control group was taught using Teacher Instructional Guide for conventional teaching strategy.

\section{Experimental Group (Visualised Case-based Learning)}

The steps to be followed include:

STEP 1:

- The teacher arranges the facilities and equipment to be used for the lesson.

- The students' prior knowledge is assessed by asking questions

- The answers provided by the students are used to ascertain if they are ready to learn the new concept.

STEP 2:

- The students are grouped randomly in groups of five or six.

- The teacher ensures that there is a relatively even distribution of students across the groups in terms of closeness, personality and academic ability.

- Each group appoints a representative.

STEP 3:

- The copies of the worksheets are distributed to each group. 
- The learners are informed of what they are about to do.

- The guidelines for the class are given to students.

- The teacher tells the students to pay attention to the movie and make observations.

STEP 4:

- The teacher turns on the video.

- A case is presented to the students.

- The students are monitored by the teacher to ensure attention is given to the video.

\section{STEP 5:}

- The students have some time to discuss the video they have just seen.

- The students write down their answers/opinions in the worksheets.

STEP 6:

- The teacher asks each representative to read out what his group has written.

- The teacher and students discuss based on what each group has in their worksheets.

- The teacher directs the flow of the discussion so that it is tailored towards the concept to be taught.

\section{STEP 7:}

- The teacher explains the concept by relating their responses to the new concept to be taught.

- The teacher provides definitions and notes.

- Practical / experiments may be carried out by the students while the teacher guides.

- The teacher is to, from time to time; refer to the case as he makes some explanations during the lesson.

STEP 8:

- The teacher evaluates by giving simple tests.

- Homework may be given to learners and submitted to teacher for marking. 


\section{Post-test}

At post-test stage, the same Chemistry Achievement Test (CAT) was given to the students a week after the last topic. The results were collated and analysed. This was carried out with a view to identifying any significant variances in the students' learning outcomes after exposure to treatment. Data from experimental group were compared to those of the control group. Duration of fieldwork was 10 weeks.

The data collected were analysed using Analysis of Covariance (ANCOVA). Estimated Marginal Means (EMM) was used to establish the magnitude of the scores while Tukey's posthoc test was used to determine the source(s) of such significant differences. All the hypotheses were tested at 0.05 level of significance.

\section{Results and Discussions}

$\mathrm{H}_{0} 1$ : There is no significant main effect of treatment on students' achievement in solubility.

Table 1: Analysis of Covariance (ANCOVA) of posttest scores of students' achievement in chemistry with treatment using pretest scores as covariates.

Tests of Between-Subjects Effects

Dependent Variable: PoCAT

\begin{tabular}{|l|l|l|l|l|l|l|}
\hline Source & $\begin{array}{l}\text { Type III Sum } \\
\text { of Squares }\end{array}$ & Df & Mean Square & F & Sig. & Squartial Eta \\
Corrected Model & $16476.197^{\mathrm{a}}$ & 18 & 915.344 & 10.543 & .000 & .433 \\
Intercept & 11108.771 & 1 & 11108.771 & 127.951 & .000 & .340 \\
PrCAT & 8991.349 & 1 & 8991.349 & 103.563 & .000 & .295 \\
Treatment & 3045.551 & 2 & 1522.776 & 17.539 & .000 & .124 \\
\hline
\end{tabular}


Table 1 shows that there is significant main effect of treatment on students' achievement in Chemistry $\left(\mathrm{F}_{(2,248)}=17.539 ; \mathrm{p}<0.05 ; \eta^{2}=0.124\right)$. This implies that the posttest scores of students' achievement in achievement differ significantly across the treatment and conventional groups with the effect size of $12.40 \%$. Also, the percentage contribution of the endogenous variable to the variance of the exogenous (dependent) measure is given as $39.2 \%$. Therefore, the null hypothesis $\mathrm{H}_{0} 1$ (a) was rejected. The magnitude of the mean scores of achievement of each group was determined and is presented in Table 2 .

Table 2 Estimated Marginal Means analysis of the posttest scores of students' achievement in chemistry by treatment

Dependent Variable: PoCAT

\begin{tabular}{|l|l|l|l|l|}
\hline \multirow{2}{*}{ Treatment } & \multirow{2}{*}{ Sean } & \multirow{3}{*}{ Std. Error } & \multicolumn{2}{|l|}{$95 \%$ Confidence Interval } \\
\cline { 4 - 5 } & & & Lower Bound & Upper Bound \\
\hline Visualised case-based & $43.74^{\mathrm{a}}$ & 1.37 & 41.04 & 46.44 \\
Conventional & $33.18^{\mathrm{a}}$ & 1.53 & 30.17 & 36.19 \\
\hline
\end{tabular}

Covariates appearing in the model are evaluated at the following values: PrCAT $=28.9251$.

PrCAT- Pretest scores of Chemistry Achievement Test

Table 2 indicates that the students in the visualised CBL group obtained the highest achievement score $(\bar{x}=43.74)$ while those of the conventional teaching (control) group obtained the lower score $(\bar{x}=33.18)$. The source of the significant difference was determined using Tukey's posthoc test and is presented in Table 3. 
Table 3. Tukey's post hoc Multiple Comparisons analysis of treatment and achievement in chemistry concepts.

Dependent Variable: PoCAT- Posttest scores of Chemistry Achievement Test

\begin{tabular}{|c|c|c|c|c|}
\hline Treatment & $\mathrm{N}$ & Mean & $\begin{array}{l}\text { Visualised } \\
\text { case-based }\end{array}$ & Conventional \\
\hline $\begin{array}{l}\text { Visualised case- } \\
\text { based }\end{array}$ & 86 & 43.74 & & $*$ \\
\hline Conventional & 59 & 33.18 & $*$ & \\
\hline
\end{tabular}

Based on observed means.

The error term is Mean Square $($ Error $)=122.20$.

Table 3 reveals that not all the possible pairs of groups are significantly different from one another. The visualised CBL group significantly did better $(\bar{x}=43.74)$ than those in the conventional group. This further reveals that significant effect seen on Table 1 was due to the differences between visualised CBL strategy and conventional teaching groups.

The findings of this study showed that there is significant main effect of treatment on students' achievement in chemistry. The posttest scores of students' achievement in chemistry significantly differ between the treatment group and control group. The students in the visualised CBL group obtained the higher achievement score $(\bar{x}=43.74)$ than those in the conventional teaching (control) group $(\bar{x}=33.18)$. One can therefore submit that both visualised case-based learning (visualised CBL) is more efficacious in improving students' achievement in chemistry than the conventional strategy. Perhaps due to the inquiry-based nature of visualised case-based strategies. Generally, inquiry-based strategies have been known to enhance students' learning outcomes (Burrowes, 2003; Brickman, Gormally, Armstrong and Hallar, 2009). In many chemistry classrooms in Nigeria, it appears that the use of conventional, non-learner-centered, obsolete strategies is prevalent. Students often find chemistry lessons boring and abstract. It also 
seems that students often participate by answering questions based on knowledge acquisition instead of engaging in activities that enhance problem-solving, critical thinking, mental reasoning and transfer of learning. Hence, meaningful learning is not achieved. While using this strategy, learners were not passive, and the students owned their learning. The engaging nature of the strategy elicited the application of suitable cognitive skills while learning in the classroom.

In the course of the study, students in the experimental groups (visualised CBL), expressed renewed enthusiasm. They were happy about doing things by themselves. They were impressed and motivated by the fact that they could proffer workable solutions to new problems. Since they worked in groups, the erstwhile 'introvert' members of the class 'came out of their shells' to participate during in the practical and discussions sessions.

Furthermore, the findings of this study are in line with those of Rybosczyk et al (2007) which showed that students who used the CBL exhibited a significantly greater learning gain than those who were not taught using CBL. The researchers also submitted that students were more likely to answer a question addressing misconceptions about cellular respiration correctly when compared to the conventional method group. Turkmen and Usta (2007) laid credence to the notion that when technology is introduced in classroom activities, there could be motivation and a conducive environment for students to learn, communicate, and share their knowledge and understanding in a wide variety of ways. However, Geelan and Mukherjee (2010) obtained a contrary result from their experiment on the use of a computer-based scientific visualization. The researchers concluded that teaching with visualizations did not make any significant impact on students' learning outcomes relative to teaching without visualization.

Visualised CBL appeared to have a better impact on students' achievement in chemistry perhaps because the video clips used during the lesson created a more relaxing environment than in the conventional class, whereby the students paid rapt attention. This could have also promoted a better understanding of the concept. Also, the topic was presented in a way that made the students able to relate and connect chemistry to everyday life. They were provided the opportunity to think beyond the classroom and come up with their own opinions. This is in line with the suggestions of Woldeamanuel, Atagana and Engida (2013). In visualised CBL, transfer of learning was more pronounced than in the conventional group and misconceptions were derived from the students and corrected appropriately. In addition, the video also elicited discussions 
among the students. Though guided by the teacher, students were encouraged to express their different views which were examined. Incorrect or alternative views were cautiously corrected by the teacher and this, to a large extent, improved their knowledge of the concept. In this study, it was observed that after the students watched the video clips, there was a high level of readiness to learn the topic for the day.

\section{Implications of the findings}

Visualised Case-Based Learning strategy is efficacious in improving students' learning outcomes in this case, achievement. Also, the use of videos in a case-based learning chemistry class improved students' achievement.

Secondly, teachers can now recognise the importance of providing opportunities for transfer of learning by relating concepts taught in the classroom to everyday life. By so doing, students can see and identify connections between what they are taught in the chemistry class and the outside world thereby creating a positive reinforcement.

\section{Conclusion}

From the results obtained in this study, it was concluded that constructivist-based strategies are efficacious in making students' learning outcomes better than the regular conventional teaching strategies. Achievement scores obtained from students taught with Visualised CBL strategy were higher than those obtained from their counterparts in the conventional group.

\section{Recommendations}

1. Pre-service as well as in-service teachers' curriculum should be updated to include training in current approaches/methodologies/strategies to chemistry teaching.

2. Teachers should be educated on how to formulate cases for teaching various chemistry concepts. Using these cases, teachers would be able to make chemistry concepts less abstract for students.

3. Cases can be used as adjunct learning resources in virtual or online classes.

4. Due to the poor state and inadequacy of infrastructure such as electricity, laboratory and laboratory equipment, computers and other forms of classroom technology, the Federal and state ministries of education should carefully look into the deplorable conditions 
under which future science professionals learn and also develop operational and permanent policies that would make learning be better.

\section{Suggestions for further study}

For further research, this study could be replicated in geographical locations other than Ibadan, Nigeria. Also, researchers may consider comparing the effects of Visualised CBL strategy and other related instructional strategies such as flipped classroom, blended learning and so on. Finally, studies could be done on the effect of this strategy on other students' learning outcomes such as attitude, self-efficacy, science process skills and so on.

\section{References}

Abram, S. (2012). Benefits of using video in the classroom. Retrieved Oct. 14, 2015, from http://www.onlineuniversites.com/blog/2012/09/11-reasons-every-educator-needs-videostrategy/

Achimugu, L. (2012). Strategies for effective conduct of practical chemistry works in senior secondary schools in Nigeria. Journal of the Science Teachers Association of Nigeria 47(1):126-136

Ali, T. (2012). A case study of the common difficulties experienced by high school students in chemistry classroom in Gilgit-Baltistan (Pakistan). SAGE Open 2(2): 1-13

Allchin, D. (2013). Problem-and case-based learning in science: an introduction to distinctions, values, and outcomes. CBE—Life Sciences Education, 12(3): 364-372.

Aluko, K. O. (2008) Teaching chemistry in secondary schools: a case for cooperative instructional strategy. Ethiop. J. Educ. \& Sc. 3(2): 31-38

Berk, R. A. (2009). Multimedia teaching with video clips: TV, movies, YouTube, and $\mathrm{mtvU}$ in the college classroom. International Journal of Technology in Teaching and Learning $5(1): 1-21$.

Brickman, P., Gormally, C, Armstrong, N. and Hallar, B. (2009). Effects of inquiry-based learning on students' science literacy skills and confidence. International Journal for the Scholarship of Teaching and Learning 3(2):1-22 
Burrowes, P. A. (2003). A student-centered approach to teaching general biology that really works: Lord's constructivist model put to a test. The American Biology Teacher, 65(7):491502

Cam, A. and Geban, O. (2013). Effectiveness of case-based learning instruction on students' understanding of solubility equilibrium concepts. H. U. Journal of Education, 44:97-108

Cruse, E. (2013) Using educational video in the classroom: theory, research and practice. Retrieved Oct. 21, 2015, from

\section{http://www.safarimontage.com/pdfs/training/UsingEducationalVideoInTheClassroom.pdf}

Day, S. B. and Goldstone, R, L. (2012) The Import of Knowledge Export: Connecting findings and theories of transfer of learning. Educational Psychologist, 47(3): 153-176.

Ezeudu, F. O. and Obi T. N. (2013). Effect of gender and location on students' achievement in chemistry in secondary schools in Nsukka local government area of Enugu state, Nigeria. Research on Humanities and Social Sciences, 3(15):50-55

Geelan, D.and Mukherjee, M. (2010). Measuring the effectiveness of computer-based scientific visualisations for conceptual development in Australian chemistry classrooms. Paper presented at Global Learn Asia Pacific 2010, AACE, Parkroyal Hotel, Penang Abas, Zoraini Wati, Jung, Insung, \& Luca, Joseph (Eds.) AACE. 3536-3545.

Hajian, S. 2019 Transfer of Learning and Teaching: A Review of Transfer Theories and Effective Instructional Practices. IAFOR Journal of Education. 7(1): 93-111

Haskell, R.E. (2001) Transfer of learning: cognition, instruction and reasoning. Educational Psychology. San Diego, Academic Press.

Herreid, C.F. (2004). Can case studies be used to teach critical thinking? Journal of College Science Teaching, 33(6):12-14.

Idika, M.I, and Adesoji, F. A. (2020) Boosting students' interest in solubility concept through the usage of 8E learning cycle model-based strategy. Journal of Academic Perspectives (1)

Jegede, S.A. (2007). Students' anxiety towards the learning of Chemistry in some Nigerian Secondary Schools. Educational Research and Review 2(7):193-197. 
Kolomuc, A., Ozmen, H., Metin, M, and Acisli, S. (2012). The Effect of animation enhanced worksheets prepared based on 5E model for the grade 9 students on alternative conceptions of physical and chemical changes. Procedia - Social and Behavioural Sciences, 46:17611765 .

McLean, S. F. (2016). Case-based learning and its application in medical and health-care fields: a review of worldwide literature. Journal of Medical Education and Curricular Development, 3, JMECD-S20377.

Nbina, J.B. (2012). Analysis of poor performance of senior secondary students in chemistry in Nigeria. Indexed African Journals Online, 6.4:324-334.

Nbina, J.B. and Viko, B. (2010). Effects of instruction in metacognitive self-assessment, strategy on chemistry students' self-efficacy and achievement. Academia Arena. 2.11.

Nnoli, J.N. (2015) Effective application of stem education through assessment of chemistry material resources and the level of acquisition of entrepreneurial skills. Towards effective application of STEM Education Research: paper presented at the $56^{\text {th }}$ Annual Conference of Science Teachers' Association of Nigeria (STAN), Awka. 2015. Z.C. Njoku. Ed. Awka: STAN: 202-209

Okediji, A.A. (2015) Effects of case-based and observational learning strategies on students' attitude to and achievement in chemistry in secondary schools in Lagos state, Nigeria. Ph.D. Thesis to the Department of Teacher Education, submitted to the Faculty of Education of the University of Ibadan.

Olaleye, B.O. (2012). Enhancing teachers" knowledge for using multiple representations in teaching chemistry in Nigerian senior secondary schools. Ph.D. Thesis submitted in School of Education, Faculty of Education and Arts, Edith Cowan University Perth, Western Australia. Retrieved from Oct 14, 2015 from http://ro.ecu.edu.au/theses/494

Omwirhiren, E. M. and Ibrahim, K. U. (2016). The Effects of Two Teachers' Instructional Methods on Students' Learning Outcomes in Chemistry in Selected Senior Secondary School in Kaduna Metropolis, Nigeria. Journal of Education and Practice, 7(15): 1-9.

Perkins, D.N. and Salomon, G. (1992). Transfer of learning. Contribution to the International Encyclopaedia of Education, $2^{\text {nd }}$ Ed. Oxford, England: Pergamon Press. 
Rybosczyk, B.J; Baines, A., McVey, M. Thompson, J., and Wilkins, H. (2007). Can a case-based approach increase student learning outcome and comprehension of cellular respiration and comprehension of cellular respiration concepts. Biochemistry and Molecular Biology Education, 35(3):181-186.

Sharma, A. (2015). Essay transfer of learning: types and theories of transfer of learning. Retrieved on Feb. 20, 2016 from theories/594.

Steiner, G. (2001) Transfer of Learning, Cognitive Psychology of, International Encyclopedia of the Social \& Behavioral Sciences. 15845-15851.

Turkmen, H. and Usta, E. (2007). The role of learning cycle approach overcoming misconceptions in science. Kastamonu Education Journal: 15(2):491-500.

Turkoquz, S. (2012). Learn to teach chemistry using visual media tools. Chemistry Education Research and Practice. 13:401-409.

Williams, B. (2005). Case based learning - a review of the literature: is there scope for this educational paradigm in prehospital education? Emergency Medicine Journal. 22(8): 577581.

Woldeamanuel, M., Atagana, H. and Engida, T. (2013). Students' anxiety towards the learning of chemistry in some Ethiopian universities. African Journal of Chemical Education, 3(2):28-38.

Yadav, A., Lundeberg, M., DeSchryver, M., Dirkin, K., Schiller, N.A., Maier, K., and Herreid, C.F. (2007). Teaching science with case studies: A national survey of faculty perceptions of the benefits and challenges of using case studies. Journal of College Science Teaching, 37(1):34-38.

Yalcinkaya, P.S, Geban, O. and Ozkan, I. (2012). Is Case-Based Instruction effective in enhancing high school students' motivation toward chemistry? Science Education International, 23(2): 102-116. 